\title{
Survival in sinoatrial disorder (sick-sinus syndrome)
}

\author{
DAVID B SHAW, RURY R HOLMAN, JIM I GOWERS
}

\section{Summary and conclusions}

A total of 381 patients with established (156) or potential (225) sinoatrial dysfunction were included in a 10-year prospective survey to determine the course of the disease and the benefits of pacing. With the exclusion of nine patients who were lost to follow-up, 61 were fitted with pacemakers.

The overall survival of patients with established and potential dysfunction was similar and apparently indistinguishable from that of the normal population. Pacemaker implantation had little discernible effect on mortality though it reduced some incapacitating symptoms.

These findings suggest that sinoatrial dysfunction is a relatively benign condition. Hence pacing should probably not be adopted as a routine measure but be reserved for patients with troublesome symptoms.

\section{Introduction}

Sinoatrial dysfunction (sick-sinus syndrome) accounts for about half of all pacemakers implanted in the USA. ${ }^{1}$ In many instances incapacitating symptoms are the indication for treatment, and the response may be dramatic and rewarding. Increasingly, however, unsuspected sinoatrial dysfunction is being discovered, particularly by ambulant 24-hour tape monitoring. ${ }^{2}$ In such cases pacemaker implantation may be recommended for fear that a prolonged period of sinus arrest or other arrhythmias will prove fatal. In heart block the mortality of patients without pacemakers is high, ${ }^{3}$ but the course of sinoatrial disease is largely unknown. ${ }^{145}$ Nevertheless, a poor prognosis has been

\footnotetext{
Cardiac Department, Royal Devon and Exeter Hospital, Wonford, Exeter EX2 5DW

DAVID B SHAW, MD, FRCP, consultant physician

RURY R HOLMAN, MB, MRCP, medical registrar Epidemiology Division, Institute of Biometry and Community
Medicine, University of Exeter

JIM I GOWERS, MSC, statistician
}

suggested irrespective of elective pacing, ${ }^{6} 78$ whereas Gann et $a l,{ }^{9}$ in a retrospective survey, found the outlook to be good.

We have conducted a 10-year prospective survey to assess survival in paced and unpaced patients with sinoatrial disorder.

\section{Patients and methods}

Patients with bradycardia associated with slow sinus and atrial rates were recruited from the Devon Heart Block and Bradycardia Survey ${ }^{10} 11$ during 1968-76. We studied 381 patients, all of whom had persistent sinus bradycardia (atrial rate under 56 beats/minute) in the absence of recent myocardial infarction or cardioactive drug treatment -for example, digitalis and beta-blocking agents. They were divided into two groups.

Patients in group 1 were considered to have established chronic sinoatrial disorder as defined by bradycardia with one or more of the following abnormalities: (1) periods of sinus arrest or sinoatrial block, in which atrial activity stopped for two seconds or more, recorded by routine electrocardiography; (2) profound atrial slowing (under 40 beats/minute) with or without junctional rhythm, recorded by routine electrocardiography; and (3) tachyarrhythmias-namely, atrial fibrillation, atrial flutter, or paroxysmal atrial or ventricular tachycardia. The detection of sinus arrest or extreme bradycardia with 24-hour tape monitoring alone did not qualify the patient for inclusion in this group.

Patients in group 2 had chronic sinus bradycardia as defined above but lacked any of the conditions for inclusion in group 1 .

Group 1 consisted of 156 patients. Of these, 68 had sinus arrest, 70 had tachyarrhythmia, and 56 had junctional rhythm. Group 2 consisted of 225 patients. Sixty-one patients from the two groups were fitted with pacemakers.

Survival times were calculated from the date of admission to the survey to the date of the last follow-up examination or death, and the date of pacemaker insertion, if any, noted. In the absence of complications patients were normally seen once a year. Nine patients were lost to follow-up, four of whom emigrated. Of these nine patients, two were from group 1 and seven from group 2; none were fitted with pacemakers. Patients were paced on clinical grounds throughout the study, but in later years a more aggressive policy towards pacing was adopted. Consequently, in years 1-3 only one patient was paced, and in years 6-8 29 patients were paced (21 in group 1).

Survival was analysed with life tables, ${ }^{12}$ the median follow-up time being five years. Survival curves were compared with the continuous form of the log-rank test. ${ }^{13}{ }^{14}$ Mortality figures for a normal population of the same age and sex distribution were calculated from the Registrar General's decennial supplement. ${ }^{15}$ 


\section{Results}

The mean age of patients in group 1 (61.7 years) was 3.5 years greater than that in group $2(58.2$ years $)$, but this was not significant ( $p<0 \cdot 1$, Kolmogorov-Smirnov test). The mean age of those fitted with pacemakers was 63.0 years. Survival in the two groups was similar, the five-year survival being about $80 \%$ (figure 1 ). The survival curves of both groups were also similar to that estimated for a normal population of similar age and sex distribution.

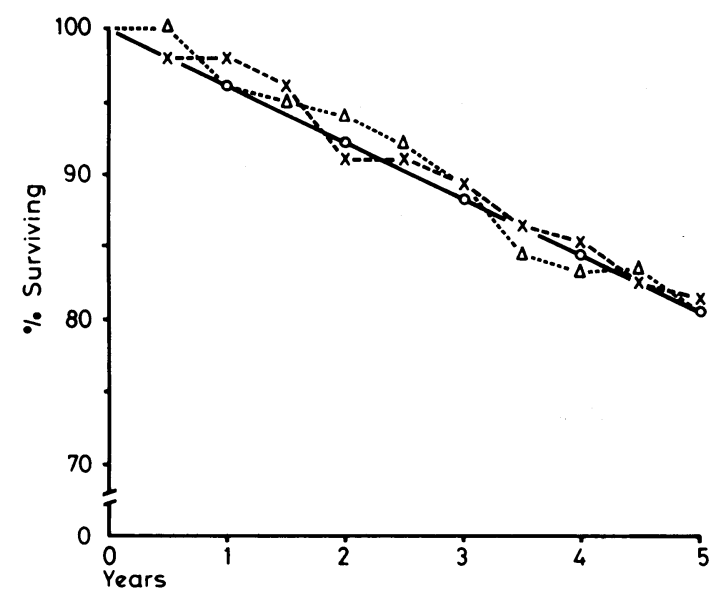

FIG 1-Observed survival curves for patients with sinoatria disorder (group $1 ; \times---\times$ ) and bradycardia (group 2; $\triangle--\triangle)$ and estimated survival curve for normal population of similar age and sex distribution $(\mathrm{O}-\mathrm{O})$.

Figure 2 shows the survival curves for unpaced and paced patients. The curves for the paced patients were calculated by taking survival from the date of implantation or from the date of admission to the survey. The results of the first method showed that these patients fared marginally worse than the unpaced patients, though this difference was not significant $(p<0 \cdot 07, \log$-rank test). There was no appreciable difference between the results for both groups when the second method of calculation was used.

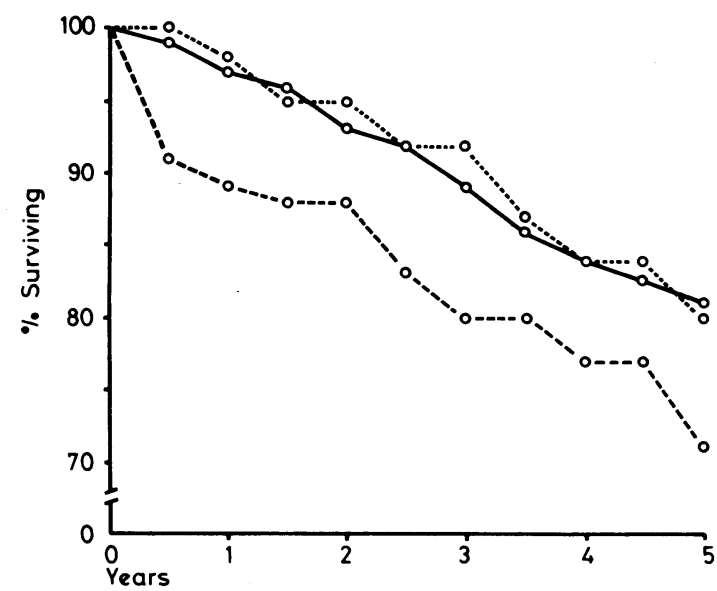

FIG 2-Survival curves for patients with pacemakers ( $\mathrm{O}-\mathrm{-O}_{\mathrm{O}}$ =from time of implantation; $0 \cdots \bigcirc=$ from time of patient's admission to study) and without pacemakers ( $\mathrm{O}-\mathrm{O}$ ).

The table shows the survivals at 42 months of the 47 patients in group 1 admitted in the first three survey years and of the 55 patients in group 1 admitted in survey years 6-8; one of the 47 had been paced, as had 21 of the 55 . The mean age of the first cohort was four years less than that of the second. This age difference was removed for the age-matched results in 30 patients and 50 patients respectively. Survival of the unpaced patients was apparently as good as that of the paced patients even when age matching was introduced.

Five-year survival in group 1 was analysed in relation to the presence or absence of a history of disturbed consciousness, coronary artery disease, and heart block. Survival in patients with dizzinessbut not complete loss of consciousness-was similar to that in patients without disturbed consciousness (five-year survival rates $87 \%$ and $84 \%$ respectively). Patients with Stokes-Adams attacks, however, had relatively poor survival at five years $(61 \% ; \mathrm{p}<0.02, \log$-rank test), though these patients tended to be older than those without such attacks (mean ages 67.5 and 59.5 years respectively). Angina had no discernible effect on mortality, survival rates being $82 \%$ in patients with angina and $83 \%$ in those without. Of the patients with myocardial infarction, $62 \%$ were alive at five years; these patients fared worse than those without such a history, but the difference failed to reach the

Mean survival ( $\pm S E$ of mean) at 42 months in 102 patients with sinoatrial disorder (group 1) admitted in survey years $1-3(n=47)$ and $6-8(n=55)$ and in 80 age-matched patients (group 1$)$ admitted in survey years $1-3(n=30)$ and $6-8(n=55)$. Results expressed as percentage of patients

\begin{tabular}{|c|c|c|c|c|}
\hline & & & Years 1-3 & Years 6-8 \\
\hline $\begin{array}{l}\text { All patients } \ldots \\
\text { Age-matched patients }\end{array}$ & 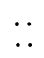 & $\because$ & $\begin{array}{l}90 \cdot 8 \pm 4 \cdot 4 \\
88 \cdot 9 \pm 4 \cdot 4\end{array}$ & $\begin{array}{l}77 \cdot 9 \pm 8 \cdot 9 \\
86 \cdot 8 \pm 8 \cdot 9\end{array}$ \\
\hline
\end{tabular}

$5 \%$ level of significance $(\mathrm{p}<0.07)$. Patients with myocardial infarction were older than those without (mean ages $67 \cdot 1$ and 60.5 years respectively). Surprisingly, heart block apparently had no great effect on survival, patients without heart block having a five-year survival rate of $78 \%$ and those with grade I and grade II or III disease having rates of $82 \%$ and $75 \%$ respectively.

The presence or absence of sinus arrest, junctional rhythm, and the bradycardia-tachycardia syndrome in group 1 had no significant effect on survival at either three or five years. The five-year mortality in patients requiring long-term diuretic treatment was $27 \%$ compared with $17 \%$ in those without evidence of cardiac failure and not requiring diuretics (not significant).

\section{Discussion}

In this study the overall survival rate of patients with established and potential sinoatrial disorder was apparently closely similar to that of the normal population. The probability of missing an $8 \%$ difference in survival at three years with the number of patients studied was no more than $1 \%$. The effects of other factors such as myocardial infarction, cardiac failure, and Stokes-Adams attacks were small, and because of age differences interpretation was difficult. Larger studies are therefore needed.

Pacemaker implantation for sinoatrial disorder does not appreciably reduce mortality, even in patients with symptoms. The long history in some forms of sinoatrial dysfunction is well known, ${ }^{16-18}$ and in our series the follow-up period may have been too short to confirm an increased mortality in patients without pacemakers. Some of the patients had been followed up for 10 years but most were followed up for only five; hence in 10-15 years' time diverging mortality rates may become apparent.

Pacemaker implantation may relieve incapacitating symptoms such as Stokes-Adams attacks so dramatically that the case for pacing on humanitarian grounds is overwhelming and does not require proof of enhanced survival. Nevertheless, the absence of a clear-cut natural history makes it difficult to decide the optimum time for pacemaker implantation in patients with lesser symptoms or in asymptomatic cases discovered by 24-hour tape monitoring. ${ }^{419}$ Our results suggest that such patients may be safely left without a pacemaker until troublesome symptoms supervene. Pacemaker implantation should therefore be reserved for symptomatic patients and the emphasis placed on developing more efficient systems.

We thank all the doctors who co-operated in this study, particularly the general practitioners for their consistent help. Financial support was provided by the DHSS and the British Heart Foundation.

Requests for reprints should be addressed to Dr D B Shaw. 


\title{
References
}

1 Kaplan BM. Sick sinus syndrome. Arch Intern Mcd 1978;138:28.

2 Macleod AA, Jewitt DE. Role of 24-hour ambulatory electrocardiographic monitoring in a general hospital. $\mathrm{Br} M e d \mathcal{F} 1978$; i:1197-9.

${ }^{3}$ Johansson BW. Complete heart block. Acta Med Scand 1966;180: suppl $451 ; 1$.

${ }^{4}$ Ferrer MI. The sick sinus syndrome: its status after ten years. Chest $1977 ; 72: 554-5$.

5 Nolan SP, Crampton RS, McGuire LB, McGann RC, Holz HC, Muller WH. Factors influencing survival of patients with permanent cardiac pacemakers. Ann Surg 1976;185:122-7.

${ }^{6}$ Krishnaswami V, Geraci AR. Permanent pacing in disorders of sinus node function. Am Heart $₹ 1975 ; 89: 579-85$.

7 Wohl AJ, Laborde J, Atkins JM, Blomqvist CG, Mullins CB. Prognosis of patients permanently paced for sick sinus syndrome. Arch Intern Med 1976;136:406-8.

${ }^{8}$ Gould L, Reddy CVR, Becker WH. The sick sinus syndrome: a study of 50 cases. F Electrocardiol 1978;11:11-14.

${ }^{\circ}$ Gann D, Tolentino A, Samet P. Electrophysiologic evaluation of elderly patients with sinus bradycardia. Ann Intern Med 1979;90:24-9.

10 Shaw DB, Eraut D. Prevalence and morbidity of heart block in Devon. Br Med F 1970;i:144-7.
11 Shaw DB, Kekwick CA. Potential candidates for pacemakers (survey of heart block and sinoatrial disorder; sick sinus syndrome). Br Heart $\mathcal{F}$ 1978;40:99-105.

12 Cutler SJ, Ederer F. Maximum utilisation of the life-table method in analysing survival. $f$ Chronic Dis 1958;11:699-712.

13 Cox DR. Regression models and life tables. $\mathscr{F} R$ Statist Soc B 1972;34:187220.

14 Peto $R$, Peto J. Asymptotically efficient rank invariant test procedures. f $R$ Statist Soc $A$ 1972;135:185-206.

15 Registrar General. Decennial supplement for England and Wales: Lifetables. London: HMSO, 1968.

16 Eraut D, Shaw DB. Sinus bradycardia. Br Heart $\mathcal{f} 1971$;33:742-9.

17 Ferrer MI. The sick sinus syndrome. Circulation 1973;47:635-41.

${ }^{18}$ Lien WP, Lee YS, Chang FZ, Lee SY, Chen CM, Tsai HC. The sick sinus syndrome (natural history of dysfunction of the sinoatrial node). Chest 1977;72:628-34.

19 Hartel G, Talvensaari T. Treatment of sinoatrial syndrome with permanent cardiac pacing in 90 patients. Acta Med Scand 1975;198:341-7.

(Accepted 12 October 1979)

\section{Postprandial gall-bladder emptying in patients with gall stones}

\author{
D P MAUDGAL, R M KUPFER，P L ZENTLER-MUNRO， T C NORTHFIELD
}

\section{Summary and conclusions}

Gall-bladder emptying in response to a standard meal was assessed in 34 patients with radiolucent gall stones and 34 matched controls. Percentage gall-bladder emptying, derived from volume measurements made on standardised oral cholecystography, was significantly higher at 15 minutes in the patients than the controls (mean \pm SE of mean $38.0 \pm 3.7 \% \quad v \quad 28.0 \pm 3.8 \%$ ). This difference was maintained at 30 and 60 minutes.

It is concluded that postprandial gall-bladder emptying is increased in patients with cholesterol gall stones, and that this may be the cause of the small bile-acid pool found in these patients.

\section{Introduction}

Patients with cholesterol gall stones have fasting gall-bladder bile that is supersaturated with cholesterol ${ }^{1}$ and a reduced bile-acid (BA) pool size. ${ }^{2}$ The cause of this small BA pool is unknown. An inverse relation exists between the size and recycling frequency of the BA pool. ${ }^{3}$ Thus an increased recycling frequency might cause a small pool by feedback inhibition of the synthesis of BA. Since the gall bladder is the storage organ for the BA pool, its emptying after a meal may determine the recycling frequency and hence the size of the pool.

We therefore tested the hypothesis that postprandial gallbladder emptying is increased in patients with gall stones by

\footnotetext{
Norman Tanner Gastroenterology Unit, St James's Hospital, and Department of Medicine, St George's Hospital Medical School, London SW17 ORE

D P MAUDGAL, MRCP, senior medical registrar

R M KUPFER, MA, MRCP, research registrar

P L ZENTLER-MUNRO, MA, MRCP, research senior registrar

T C NORTHFIELD, MD, FRCP, consultant physician and senior lecturer
}

comparing the response to a standard meal in 34 such patients and 34 controls. To limit the study as far as possible to patients with cholesterol gall stones we included only those with radiolucent stones, since $80 \%$ of such stones contain over $70 \%$ cholesterol. ${ }^{4}$ We were careful to match the patients and controls in pairs for age, sex, obesity, and race because the prevalence of cholesterol gall stones is related to these factors ${ }^{56}$ and gallbladder emptying is affected by age and sex.?

\section{Patients and methods}

We studied 34 patients with radiolucent gall stones in a gall bladder that opacified on oral cholecystography. Patients with calcified gall stones and those whose gall stones occupied over half of the gallbladder volume were excluded. We also studied 34 control subjects with dyspeptic symptoms and an unequivocally normal cholecystogram. They were matched in pairs with the patients with gall stones for age (within 10 years), height $(10 \mathrm{~cm})$, body weight $(10 \mathrm{~kg})$, race, and sex. Ten of the pairs were men and 24 women. The mean age of the patients was 52 years and of the controls 53 years; the corresponding mean weights were $72 \mathrm{~kg}$ and $68 \mathrm{~kg}$, and the corresponding mean heights $167 \mathrm{~cm}$ and $164 \mathrm{~cm}$. Six patients and six controls were over $120 \%$ of their ideal body weight. Written informed consent was obtained from all subjects before they entered the study.

We assessed gall-bladder emptying by means of carefully standardised oral cholecystography. The subject was supine, and angulation over the $x$-ray film was adjusted by means of a wooden wedge to give an angle of $45^{\circ}$. The $x$-ray tube was adjusted to a distance of $100 \mathrm{~cm}$ from the plate. In premenopausal women cholecystography was carried out within 10 days after the onset of the menstrual cycle, thus eliminating differences in emptying during different phases of the menstrual cycle. ${ }^{8} X$-ray films were taken in the fasting state and 15 , 30 , and 60 minutes after a standard liquid test meal (Lundh), a pilot study having shown that maximum emptying always occurred within the first hour after the meal. The gall bladder was outlined on tracing paper. Area was measured by means of a grid system, and volume was calculated by the method described and validated by Silva. ${ }^{9}$ Both measurements were made by someone unaware of the diagnosis. Statistical analysis was carried out by using the Wilcoxon signed-rank test for paired samples. 